\title{
PENINGKATAN KESEHATAN MASYARAKAT MELALUI PENGETAHUAN PENYAKIT ZOONOSIS DI KECAMATAN KEPOHBARU KABUPATEN BOJONEGORO
}

\section{IMPROVING COMMUNITY HEALTH THROUGH KNOWLEDGE OF ZOONOSIS DISEASE IN KEPOHBARU DISTRICT BOJONEGORO DISTRICT}

\author{
Oky Setyo Widodo \\ Fakultas Kedokteran Hewan \\ Sunaryo Hadi Warsito \\ Fakultas Kedokteran Hewan \\ Shelly Wulandari \\ Fakultas Vokasi
}

\begin{abstract}
ABSTRAK
Tujuan utama dalam kegiatan pengabdian kepada masyarakat ini adalah dapat meningkatkan wawasan masyarakat di Kecamatan Kepohbaru Bojonegoro tentang penyakit zoonosis. Harapannya dengan bertambahnya pengetahuan warga, maka tingkat kesehatan masyarakat secara umum bias menjadi lebih baik. Metode pelaksanaan yang akan digunakan dalam program pengabdian masyarakat ini adalah penyuluhan dan diskusi. Tujuan dari penyuluhan yang dilakukan kepada warga masyarakat adalah memberikan gambaran umum tentang penyakit zoonosis dan selanjutnya dilakukan diskusi yang mendalam tentang gejala klinis, penanganan, pencegahan, dan pengobatan penyakit zoonosis. Setelah kegiatan selesai, akan dilakukan monitoring melalui penerjunan mahasiswa KKN BBM Universitas Airlangga.
\end{abstract}

Kata kunci: Penyakit zoonosis, Penyuluhan, Kecamatan Kepohbaru, Kabupaten Bojonegoro

\begin{abstract}
The main objective in this community service activity is to improve the insight of the people in Kepohbaru Bojonegoro sub-district about zoonotic diseases. The hope is that with the increasing knowledge of citizens, the level of public health in general can be better. The implementation method that will be used in this community service program is counseling and discussion. The purpose of counseling conducted to the community is to provide a general description of zoonotic diseases and then conduct an in-depth discussion about the clinical symptoms, handling, prevention and treatment of zoonotic diseases. After the activity is completed, monitoring will be carried out through the transfer of students of BBM KKN Universitas Airlangga.
\end{abstract}

Keywords: Zoonotic Disease, Extension, Kepohbaru District, Bojonegoro Regency

\section{PENDAHULUAN}

Kabupaten Bojonegoro merupakan sebuah kabupaten di Provinsi Jawa Timur, Indonesia. Ibu kotanya adalah Bojonegoro. Kabupaten ini berbatasan dengan Kabupaten Tuban di utara, Kabupaten Lamongan di timur, Kabupaten Nganjuk, Kabupaten Madiun, dan Kabupaten Ngawi di selatan, serta Kabupaten Blora (Jawa Tengah) di barat. Bagian barat Bojonegoro (perbatasan dengan Jawa Tengah).

Keadaan topografi Kabupaten Bojonegoro didominasi oleh keadaan tanah yang berbukit yang berada di sebelah selatan (Pegunungan Kapur Selatan) dan sebelah utara (Pegunungan Kapur Utara) yang mengapit dataran rendah yang berada di sepanjang aliran Bengawan Solo yang merupakan daerah pertanian yang subur. Wilayah Kabupaten Bojonegoro didominasi oleh lahan dengan kemiringan yang relatif datar. Hal tersebut dapat ditunjukkan bahwa 91,26\% wilayah Kabupaten Bojonegoro memiliki kemiringan antara 0-15\%. Permukaan tanah di Kabupaten Bojonegoro rata-rata berada pada ketinggian dari permukaan laut yang relatif rendah, yaitu berada pada ketinggian antara 25-500 $\mathrm{m}$ dari permukaan laut.

Sungai bengawan Solo mengalir dari selatan, menjadi batas alam dari Provinsi Jawa Tengah, kemudian mengalir ke arah timur, di sepanjang wilayah utara Kabupaten 
Bojonegoro. Bagian utara merupakan Daerah Aliran Sungai Bengawan Solo yang cukup subur dengan pertanian yang ekstensif. Kawasan pertanian umumnya ditanami padi pada musim penghujan, dan tembakau pada musim kemarau. Bagian selatan adalah pegunungan kapur, bagian dari rangkaian Pegunungan Kendeng. Bagian barat laut (berbatasan dengan Jawa Tengah) adalah bagian dari rangkaian Pegunungan Kapur Utara.

Kabupaten Bojonegoro terdiri atas 28 kecamatan, yang dibagi lagi atas sejumlah 419 desa dan 11 kelurahan. Pusat pemerintahan di Kecamatan Bojonegoro. Kecamatan Kepohbaru merupakan salah satu kecamatan yang terdapat di Kabupaten Bojonegoro. Kecamatan Kepohbaru merupakan kecamatan dengan penduduk bermata pencaharian sebagai petani terbesar di Kabupaten Bojonegoro. Jarak antara Kecamatan Kepohbaru dengan pusat pemerintahan Kabupaten Bojonegoro kurang lebih $40 \mathrm{~km}$. Luas wilayah Kecamatan Kepohbaru sekitar 79,64 km² dengan jumlah penduduk 71.525 jiwa. Dari sisi perekonomian, Ibukota Kecamatan Kepohbaru termasuk salah satu Ibukota Kecamatan yang ramai di Kabupaten Bojonegoro. Hal itu bisa dilihat dari semaraknya perdagangan yang ada pusat kecamatan ini. Pasar kecamatan yang ramai setiap hari, kompleks pertokoan, beberapa swalayan, dan bahkan outlet berskala nasional sudah masuk di Kota Kecamatan ini. Peta Kecamatan.

Desa Balongdowo dan Desa Krangkong merupakan daerah sentra pertanian padi dan tembakau. Secara umum tanaman padi mendominasi di setiap lahan persawahan. Berdasarkan data kecamatan, sekitar $85 \%$ dari total jumlah penduduk pekerja produktif di Desa Balongdowo dan Desa Krangkong memiliki mata pencaharian sebagai petani dan buruh tani. Jumlah penduduk Desa Balongdowo dan Desa Krangkong sekitar 5.500 jiwa dengan kurang lebih 1.300 kepala keluarga. Perbandingan penduduk berjenis kelamin laki-laki dan perempuan adalah 48,6:51,4. Batas wilayah Desa Balongdowo dan Desa Krangkong di sebelah utara berbatasan dengan Desa Jipo, pada sisi selatan berbatasan dengan Desa Simorejo, pada sisi barat berbatasan dengan Desa Nglumber, dan pada sisi sebelah timur berbatasan dengan Desa Jatipayak.

Rata-rata para petani atau buruh tani yang berada di Desa Balongdowo dan Desa Krangkong memiliki hewan ternak yang dipelihara. Jenis hewan ternak tersebut antara lain kambing, domba, sapi, itik, dan ayam. Hewan ternak tersebut dapat dijadikan sebagai sumber penghasilan tambahan selain bertani. Biasanya, untuk keperluan-keperluan tertentu ternak tersebut dapat langsung dijual dan dapat menghasilkan uang daripada harus menunggu waktu panen tiba. Karena sifatnya hanya usaha sampingan, maka kegiatan peternakan yang dilakukan oleh warga masih dikelola secara tradisional.

\section{PERMASALAHAN MITRA}

Berdasarkan hasil diskusi dengan kepala desa dan beberapa masyarakat sekitar pada saat kegiatan KKN BBM Universitas Airlangga ke-55 di bulan Januari 2017, teridentifikasi beberapa permasalahan, salah satunya merupakan masalah kesehatan. Kesehatan dalam hal ini mencakup kesehatan masyarakat itu sendiri, kesehatan lingkungan, dan kesehatan pada hewan ternak. Rata-rata masyarakat masih mengabaikan aspek-aspek kesehatan dalam kehidupan sehari hari. Salah satu contohnya adalah (1) masih banyak masyarakat yang memiliki tempat tinggal yang sangat berdekatan dengan lokasi kandang ternaknya tanpa adanya sanitasi yang bagus, (2) kotoran ternak yang hanya ditimbun di dekat kandang tanpa adanya penanganan lebih lanjut yang dapat menyebabkan terjadinya penyakit, (3) fasilitas sanitasi kandang masih sangat kurang ketika masyarakat bersentuhan secara langsung dengan ternaknya, serta (4) minimnya informasi atau pengetahuan peternak tentang penyakit yang dapat menular dari hewan ke manusia dan dari manusia ke hewan (zoonosis). Permasalahan-permasalahan tersebut merupakan permasalahan yang harus segera memiliki solusi, sehingga diharapkan setelah selesainya kegiatan pengabdian masyarakat ini, warga masyarakat Kecamatan Kepohbaru khususnya pada Desa Balongdowo dan Desa Krangkong dapat mengetahui dan memahami tentang penyakitpenyakit zoonosis serta dapat mengantisipasinya. Tim yang akan terlibat dalam program pengabdian masyarakat ini memiliki pengalaman dan bidang keahlian yang sesuai dengan permasalahan masyarakat Desa Balongdowo dan Desa Krangkong Kecamatan Kepohbaru.

\section{SOLUSI YANG DITAWARKAN}

Berdasarkan analisis terhadap suatu akar permasalahan seperti yang telah diuraikan diatas, maka solusi yang ditawarkan untuk dapat meningkatkan taraf kesehatan warga adalah dengan cara memberikan penyuluhan tentang penyakit-penyakit zoonosis meliputi jenis-jenis penyakit, gejala klinis, penularan, serta pengobatannya; pembagian buku modul yang berisi tentang gambaran penyakit zoonosis sehingga masyarakat menjadi lebih mudah memahaminya; serta membagikan stiker dan pin yang berisi imbauan untuk hidup sehat dari ternak hingga ke manusianya.

Zoonosis adalah infeksi penyakit yang dapat ditularkan di antara hewan vertebrata dan manusia atau sebaliknya (Soejodono dkk., 2004). Penyakit zoonosis adalah ancaman gangguan kesehatan yang saat ini di alami oleh banyak negara, yang di dalamnya termasuk Indonesia. Yaitu satu jenis penyakit yang sumbernya dari binatang dengan sifat menular, dan jika didiamkan akan menjadi penyakit akut 
bahkan selanjutnya bisa berakibat fatal. Penularan ini juga dua arah, artinya tak hanya dari binatang ke manusia, akan tetapi juga sebaliknya, dari manusia ke binatang. Penyakit zoonosis mendapat perhatian secara global dalam beberapa tahun terakhir baik mengenai epidemiologi, mekanisme transmisi penyakit dari hewan ke manusia, diagnosa, pencegahan dan kontrol (Kusumamiharja, 1992).

Dengan latar belakang yang cukup serius, maka pihak-pihak yang terkait dengan kesehatan sangat concern dengan satu jenis penyakit ini. Contoh ancaman serius jenis penyakit zoonosis itu di antaranya adalah MERSCoV, Ebola, Anthrax, Toxoplasmosis, Rabies, Brucellosis, Sars, dan masih banyak lagi. Banyak dari contoh sakit yang ada dalam zoonosis itu merupakan penyakit yang memiliki dampak multi-aspek. Yaitu mulai dari banyaknya jumlah warga yang sakit, menurunnya daya saing global, timbulnya banyak korban jiwa.

\section{METODE PELAKSANAAN}

Berdasarkan analisis terhadap hasil-hasil penelitian yang terkait dan dari diskusi yang mendalam dengan para warga masyarakat Desa Balongdowo dan Desa Krangkong Kecamatan Kepohbaru Kabupaten Bojonegoro, teridentifikasi permasalahan utama terkait kesehatan masyarakat dan kesehatan hewan, yaitu minimnya informasi atau pengetahuan peternak tentang penyakit yang dapat menular dari hewan ke manusia dan dari manusia ke hewan (zoonosis).

Untuk mengatasi permasalahan tersebut, makas solusi yang ditawarkan melalui program pengabdian masyarakat dari Lembaga Pengabdian, Pendidikan, Pelatihan dan Pengembangan masyarakat (LP4M) Fakultas Kedokteran Hewan universitas Airlangga adalah memberikan penyuluhan tentang penyakit-penyakit zoonosis meliputi jenis-jenis penyakit, gejala klinis, penularan, serta pengobatannya, pada saat penyuluhan terjadi interaksi secara langsung antara warga masyarakat dan tim pengabdian masyarakat sehingga dapat dibuka forum diskusi dan Tanya jawab terkait masalah kesehatan yang dihadapi secara langsung oleh warga masyarakat; pembagian buku modul yang berisi tentang gambaran penyakit zoonosis sehingga masyarakat menjadi lebih mudah memahaminya; serta membagikan stiker dan pin yang berisi imbauan untuk hidup sehat dari ternak hingga ke manusianya.

Kegiatan pengabdian kepada masyarakat ini telah di lakukan pada tanggal 30 Juli 2017 bertepatan dengan jadwal penerjunan lapangan mahasiswa KKN BBM Universitas Airlangga. Penyuluhan bertempat di balai pertemuan warga dan dihadiri 42 warga masyarakat sekitar.

Program pengabdian masyarakat ini dilaksanakan secara bermitra atau berkolaborasi antara tim pelaksanaan pengabdian masyarakat yang terdiri dari dosen-dosen
Fakultas Kedokteran Hewan dan Fakultas Vokasional Universitas Airlangga dengan warga masyarakat Desa Balongdowo (Mitra 1) dan Desa Krangkong (Mitra 2) Kecamatan Kepohbaru. Peran dari mitra tersebut antara lain memberikan gambaran nyata tentang permasalahanpermasalahan yang dihadapi oleh dalam usaha peningkatan kesehatan masyarakat, dan memberikan masukan-masukan tentang rencana program yang tepat sasaran. Setelah melakukan diskusi dengan kepala desa dan perwakilan warga maka muncul permasalahan utama bagi para warga masyarakat yaitu tentang kesehatan masyarakat dan kesehatan hewan, yaitu minimnya informasi atau pengetahuan peternak tentang penyakit yang dapat menular dari hewan ke manusia dan dari manusia ke hewan (zoonosis).

Metode pelaksanaan yang akan digunakan dalam program pengabdian masyarakat ini adalah penyuluhan dan diskusi. Tujuan dari penyuluhan yang dilakukan kepada warga masyarakat adalah memberikan gambaran umum tentang penyakit zoonosis dan selanjutnya dilakukan diskusi yang mendalam tentang gejala klinis, penanganan, pencegahan, dan pengobatan penyakit zoonosis, dengan demikian pengetahuan para warga masyarakat dapat semakin bertambah dan mendorong untuk dapat lebih meningkatkan kesehatan di lingkungan masyarakat dan kesehatan ternaknya. Penyuluhan juga penting dilakukan untuk dapat mengubah pola pikir para warga masyarakat yang rata-rata masih konvensional hingga dapat menerima transfer pengetahuan dari tim pengabdian masyarakat dari Fakultas Kedokteran Hewan Universitas Airlangga.

Pelaksanaan program pengabdian masyarakat yang bersumber pada bantuan pendanaan perguruan tinggi negeri (BPPTNBH) tahun 2017 yang dilakukan oleh dosen pembina pembangunan desa (DP2D) KKN BBM Universitas Airlangga merupakan salah satu wujud pengamalan tri dharma perguruan tinggi di bidang pengabdian masyarakat, khususnya warga masyarakat Desa Balongdowo dan Desa Krangkong Kecamatan Kepohbaru Kabupaten Bojonegoro. Tim dosen yang terlibat dalam program pengabdian masyarakat ini memiliki kompetensi, kepakaran, dan pengalaman di bidang kesehatan masyarakat dan kesehatan hewan. Ketua tim pengabdian masyarakat ini memiliki latar belakang pendidikan ilmu biologi reproduksi dan memiliki pengalaman dalam kegiatan pengabdian masyarakat sejak tahun 2014. Anggota tim pengabdian masyarakat merupakan dosen-dosen yang memiliki pengalaman penelitian, pengalaman lapangan, dan pengetahuan yang luas mengenai ilmu penyakit, kesehatan masyarakat dan kesehatan hewan.

\section{PELAKSANAAN PROGRAM}

Kegiatan pengabdian kepada masyarakat telah dilaksanakan pada tanggal 30 Juli 2017. Bertempat di 
balai pertemuan warga desa Kedung Adem Kabupaten Bojonegoro. Pada acara ini dihadiri oleh kepala desa, perangkat desa, warga masyarakat, mahasiswa KKN BBM Universitas Airlangga, dan Dosen Pembina Pembangunan Desa (DP2D). Acara dibuka dengan sambutan dari kepala desa dan dilanjutkan sambutan oleh Dosen Pembina Pembangunan Desa (DP2D).

Rangkaian acara dalam kegiatan pengabdian kepada masyarakat ini adalah pembukaan, penyuluhan, dan diskusi. Setelah forum dibuka oleh Bapak kepala desa dilanjutkan acara selanjutnya acara utama yaitu penyuluhan mengenai penyakit zoonosis. Materi pertama tentang pendahuluan dan pengertian penyakit zoonosis disampaikan oleh drh. Shelly Wulandari, M.Si. Pada awal sesi terlihat warga masyarakat masih banyak yang belum mengetahui dan memahami tentang apa itu penyakit zoonosis, namun ketika materi penyuluhan sudah disampaikan lebih jauh terlihat warga masyarakat mulai memahami tentang penyakit zoonosis. Hal ini terbukti dengan adanya beberapa warga yang ingin bertanya meskipun forum diskusi dan tanya jawab belum dibuka.

Materi awal yang di sampaikan kepada warga ini memberikan gambaran yang mudah dipahami tentang penyakit zoonosis. Dalam sesi ini dibahas secara mendalam tentang macam penyakit zoonosis, ciri-ciri atau gejala klinisnya, serta cara pencegahan macam-macam penyakit zoonosis yang dapat menyerang manusia. Warga masyarakat menjadi tahu dan memahami bahwa ada penyakit yang dapat saling ditularkan dari hewan ke manusia dan sebaliknya. Ditampilkan juga gambar atau foto dan video sebagai media presentasi agar warga masyarakat dapat lebih mudah memahami. Materi disampaikan dengan suasana yang menyenangkan, sehingga interaksi dari pemateri dan warga masyarakat bias berlangsung dengan baik dan lancar.

Setelah rehat beberapa menit, dilanjutkan kembali dengan materi yang ke-dua. Materi ke-dua ini disampaikan oleh drh. Oky Setyo Widodo, M.Si. Topik yang disampaikan pada sesi ini adalah mengenai penyakit-penyakit zoonosis pada hewan ternak. Sesi ke dua penyampaian materi, para peserta semakin kondusif karena sudah memiliki pengetahuan sebelumnya pada penyampaian materi sesi pertama.

Proses penyampaian materi pada sesi kedua ini berjalan dengan lancar dengan antusiasme yang tinggi dari peserta. Meskipun sudah disampaikan akan diadakan forum diskusi setelah seluruh materi tersampaikan, tetap saja ada beberapa peserta yang sudah tidak sabar untuk menyampaikan pertanyaan. Para peserta memiliki semangat yang tinggi untuk memperoleh informasi karena mereka hampir setiap hari dalam segala aktivitasnya bersinggungan dengan hewan ternak. Mereka mengkhawatirkan sakit yang di derita oleh ternaknya akan dapat menular ke anggota keluarga yang lain.

Sesi yang terakhir dari rangkaian acara pengabdian kepada masyarakat ini adalah forum diskusi. Para peserta dalam hal ini adalah warga masyarakat yang pada umumnya adalah peternak dapat menyampaikan pertanyaannya untuk didiskusikan bersama. Proses diskusi berjalan dua arah, narasumber dan peserta terlibat interaksi yang baik dalam forum. Terdapat beberapa pertanyaan yang disampaikan oleh peserta dan dapat di jawab sendiri oleh peserta yang lain. Bagi peserta yang antusias dan memiliki pertanyaan yang bagus, diberikan hadiah berupa bingkisan yang sudah di persiapkan oleh tim pengabdian kepada masyarakat.

Setelah kegiatan selesai, akan dilakukan monitoring melalui penerjunan mahasiswa KKN BBM Universitas Airlangga pada periode selanjutnya. Dengan demikian dapat diketahui tingkat pemahaman dari warga masyarakat secara umum dan dapat digali lagi tentang permasalahan atau program-program yang dibutuhkan oleh warga ke depannya. Harapannya program ini dapat berlangsung secara berkesinambungan agar dapat menjadi percontohan sebagai desa binaan dari Universitas Airlangga Surabaya.

\section{KESIMPULAN}

Kesimpulan dari kegiatan pengabdian kepada masyarakat yang telah dilaksanakan adalah sebagai berikut:

1. Masih banyak warga masyarakat yang belum memahami tentang penyakit yang dapat ditularkan dari hewan ke manusia dan sebaliknya (zoonosis)

2. Sebagian warga masyarakat pada umumnya sudah mengetahui tentang sanitasi atau tata cara kebersihan lingkungan yang baik, tetapi masih belum banyak yang menerapkannya.

\section{SARAN}

Saran yang dapat disampaikan dari kegiatan pengabdian kepada masyarakat ini adalah:

1. Perlu dibentuknya kader atau petugas khusus dari kelurahan yang bertugas mengimbau dan menginformasikan tentang pentingnya kesadaran hidup sehat dan bersih.

2. Perlu di lakukan pendampingan lebih lanjut, dalam hal ini oleh mahasiswa KKN BBM yang diterjunkan di lokasi dan oleh Dosen Pembina Pembangunan Desa (DP2D) kepada warga masyarakat dapat semakin memahami pentingnya hidup sehat dan bersih guna pencegahan penyakit zoonosis.

\section{DAFTAR PUSTAKA}

Kusumamihardja, S. 1992. Parasit dan Parasitosis pada Hewan Ternak Piaraan di Indonesia. Bogor: Pusat Antar Universitas Bioteknologi Institut Pertanian Bogor Soejodono, Roso. (2004). Zoonosis. Bogor: Laboratorium Kesmavet Fakultas Kedokteran Hewan IPB. 